\title{
Políticas públicas, distribuição de renda e pobreza no meio rural brasileiro no período de 1995 a 2005
}

\author{
Renata Couto Moreira ${ }^{1}$ \\ Marcelo José Braga ${ }^{2}$ \\ Fátima M. Andrade de Carvalho ${ }^{3}$ \\ João Ricardo Ferreira de Lima ${ }^{4}$ \\ José Maria Alves da Silva ${ }^{5}$
}

Resumo: O presente trabalho buscou discutir o papel das políticas públicas no processo histórico de concentração de renda e pobreza no meio rural brasileiro. Com base nas informações das pessoas acima de 10 anos residentes nas áreas rurais das Pesquisas Nacionais por Amostra de Domicílios (PNAD), para o período de 1995 a 2005, calcularam-se os índices de desigualdade de Gini, de Theil (R e L) e os índices de pobreza de Foster-Greer-Thorbecke (1984) e de Datt (1998). Os dados e resultados indicam para a existência da relação entre a persistente condição de pobreza da população rural e as políticas agrária e econômica adotadas no período.

Palavras-chaves: elasticidade da pobreza, distribuição de renda, crescimento econômico e política agrária.

Abstract: The objective of the present work is to discuss about the role of public policies in the historic process of income concentration and poverty in the Brazilian rural territory. With basis in information about persons up to 10 years residents in rural areas from the National Research of Domiciles Sample (PNDA) for the period from 1995 to 2005, there was calculated the Gini and Theil ( $R$ and $L$ ) inequality Index, and the

${ }^{1}$ Doutora, Professora Adjunto do Departamento de Ciências da Computação da Universidade Federal de Lavras, MG.

${ }^{2}$ Doutor, Professor Adjunto do Departamento de Economia Rural da Universidade Federal de Viçosa (DER/UFV). E-mail: mjbraga@ufv.br

${ }^{3}$ Doutora, Professora Adjunto do DER/UFV. E-mail: fmac@ufv.br

${ }^{4}$ Doutor, Professor Adjunto do Departamento de Ciências Fundamentais e Sociais da Universidade Federal da Paraíba. E-mail:jricardo@cca.ufpb.br

${ }^{5}$ Doutor, Professor Adjunto do DER/UFV.E-mail: jmasilva@ufv.br 
Foster-Greer-Thorbecke (1984) and Datt (1998) poverty Index. The data and results bring the indication of the existence of the relation between the persistent condition of poverty of the rural population and the agrarian and economic policies adopted in the period.

Key-words: poverty elasticity, income distribution, economic growth and agrarian policy.

Classificação JEL: I32, I38, O15.

\section{Introdução}

A evolução histórica da economia brasileira é caracterizada por um processo de concentração de renda, que tem persistido mesmo com alterações na política econômica e flutuações no desempenho econômico. Mesmo com os picos de elevadas taxas de crescimento econômico e com os avanços tecnológicos que o País experimentou, os índices de pobreza persistiram entre os mais altos do mundo, limitando o próprio processo de desenvolvimento socioeconômico do País. Segundo Corrêa (1998), a tarefa de relacionar essa concentração histórica de renda, o crescimento econômico e a pobreza no meio rural, em uma análise do desenvolvimento econômico do País, pressupõe que se realizem pesquisas sobre sua política econômica, seu perfil distributivo e a identificação das principais variáveis explicativas nas especificidades dos cenários econômicos. A autora também observa que análises que não consideram a transferência de riqueza entre gerações deixam de considerar uma das grandes fontes de desigualdade e sua manutenção.

O interesse foi dado aos mecanismos de concentração de renda que afetam o desenvolvimento socioeconômico do País, sendo fator limitante do seu crescimento econômico de longo prazo, como tão bem discutidos por diversos autores $^{6}$. O modelo concentrador de renda, por eles discutido, trata a questão agrária no contexto de políticas públicas prioritárias ao processo de industrialização, tanto do período da década de 50 e início da de 60 pela substituição de importações, tendo o estado como mecanismo de transferência de renda do setor agrário à indústria; quanto no pós-guerra após 1964, voltado para exportaçóes, com transferência de renda dos trabalhadores para os capitalistas e tecnoburocratas, e do setor competitivo (caracterizado principalmente pela indústria nacional) para o monopolista (representado pelo estado e pelas multinacionais).

Encontra-se neste ponto a base para a explicação do nomeado "subdesenvolvimento industrializado" que se associa ao fato de o processo de industrialização não ter levado o País ao desenvolvimento, mas que, pelo

${ }^{6}$ Dentre os quais são citados: Furtado (1968), Aldana (1968), Prado Jr.(1981), Pereira (1985), Corrêa (1998). 
contrário, aprofundou as desigualdades sociais. Segundo Pereira (1985), a primazia dada aos bens de consumo de luxo resultou na estagnação da taxa de acumulação de capital e no desequilíbrio das contas do País. Nos processos dados nos países desenvolvidos, bens de capital e matérias-primas geraram mais bens de capital e mais matérias-primas, sendo possível o acúmulo de capital necessário e o aumento da taxa de acumulação desse capital. No Brasil, pelo contrário, bens de capital e matéria-prima geravam bens de luxo, produzidos por processo intensivos em tecnologia e capital, com uso reduzido de mão-de-obra e muita dependência de insumos importados. Isso levou ao desequilíbrio das contas externas e não aumentou a taxa de acumulação do capital, apoiando a prioridade ao crescimento econômico no endividamento externo. Com isso, percebe-se que no processo de desenvolvimento e crescimento econômico brasileiro, as distorções que estão sendo acuradas representam um grave entrave para a continuidade do processo de crescimento econômico do País, pelo menos às taxas equiparadas às décadas anteriores e ao crescimento da população, mínimo necessário para incluir o aumento da população em fase ativa também durante as futuras gerações.

Procura-se com este estudo subsidiar pesquisas que busquem reverter o grave quadro de crise e desigualdade social em que se encontra o Brasil nesta transição para o século XXI, com foco no setor agrícola, visto que este ocupa um quarto das pessoas economicamente ativas do País pelo de acordo com o Censo Agropecuário de 1995/1996, último realizado pelo Instituto Brasileiro de Geografia e Estatística (IBGE), antes da elaboração deste trabalho, além de ser responsável pela produção de alimentos, cujos preços são usados como base para o cálculo do custo de vida nas cidades, determinando também os salários urbanos e o próprio índice geral de preços. Neste sentido, é importante enfatizar o papel da política econômica e agrícola na evolução da estrutura da economia agrária, gerando desigualdades e alterando os parâmetros da relação ao longo do tempo.

O trabalho traz uma análise descritiva de como a desigualdade da distribuição da renda e a pobreza na agricultura brasileira mudaram de 1995 a 2005, remontando seu percurso temporal. Discute também a existência da relação entre a política agrária e a desigualdade de renda no meio rural no Brasil, atuando nos mecanismos de reprodução da desigualdade e da pobreza, com conseqüências ao crescimento econômico e ao desenvolvimento social e político do País. Aprofundando a análise, busca-se a realização de uma inferência estatística sobre a relação entre a distribuição da renda e o crescimento econômico com a pobreza no meio rural brasileiro, à luz de políticas econômicas e agrárias vigentes no País neste período.

Na próxima seção é apresentada uma perspectiva histórica da economia brasileira desde os anos 60, citando as principais políticas econômicas e agrícolas para o Brasil, e suas conseqüências no processo de concentração de renda. Na seção 3, trata-se das referências analíticas abordando desde as medidas de 
desigualdade e de pobreza, passando pela escolha do deflator e o cálculo das linhas de pobreza e da elasticidade da pobreza com relação à distribuição de renda e à renda média, até a definição e evolução da base de dados e da amostra. A seção 4 traz os resultados e as análises dos dados rurais do Brasil para o período de 1995 a 2005 e, para concluir, a seção 5 apresenta as principais conclusões da pesquisa.

\section{Perspectiva do processo histórico de concentração pessoal de renda no Brasil de 1960 a 2005}

O Brasil é marcado pelas profundas desigualdades sociais existentes desde o período de colonização. Essa desigualdade vem se propagando de forma marcante no processo de concentração de renda que o País vem experimentando em diferentes contextos macroeconômicos. A desigualdade pessoal de rendimentos no País apresentou aumentos tanto nos períodos caracterizados pela estagnação econômica, quanto nos de forte crescimento da renda (CORRÊA, 1998). Segundo Barros \& Araújo (1991) e Carvalho \& Teixeira (2005), o modelo de política agrícola que predominou no País no pós-guerra, de grande viés urbano-industrial, priorizou a adoção de políticas públicas voltadas para o mercado, em detrimento de políticas de natureza estrutural, tais como reformas nos sistemas de educação e saúde, na estrutura da posse da terra ou no desenvolvimento de um sistema efetivo de tributação fundiária e trabalhista.

Isto se fez presente tanto no modelo de industrialização por substituição de importações da década de 1950 e parte de 1960, quanto no modelo voltado para exportações instituído no pós-1964. O golpe de 1964 excluiu um caminho alternativo baseado num projeto nacional centrado na elevação do poder político e padrão de consumo das massas urbanas e rurais. Projeto a que Furtado (1964) se dedicou no Plano Trienal e em que as peças de resistência econômica e política eram a reforma agrária e as políticas públicas favorecedoras dos setores atrasados.

No entanto, houve forte redução do salário mínimo e, através da reforma monetária e tributária, as rendas especulativas de propriedade foram estimuladas e protegidas e a desigualdade da distribuição da renda aumentou, segundo estudos baseados nos dados disponibilizados nos Censos Demográficos de 1960 e $1970^{7}$. Entretanto, o compromisso com o crescimento e a industrialização como projeto nacional foi reforçado. A migração de fatores de produção para os setores mais produtivos retirava-os dos setores menos produtivos, dentre os quais destacava-se o de alimentos. A modernização da

$\overline{7}$ Ver por exemplo estudos de Fishlow (1972, 1973), Langoni $(1973,1974)$, Hoffmann (1973) e Singer (1975). 
agricultura expulsava trabalhadores que estavam ocupados na produção de alimentos, fazendo-os migrar para a cidade de forma desordenada, o que causava, assim, aumento da pobreza junto àqueles que não conseguiam se alocar no mercado de trabalho urbano.

Dentre as políticas agrícolas adotadas neste contexto destacam-se as voltadas à grande exploração agromercantil com a manutenção de uma taxa de câmbio cronicamente sobre-valorizada para facilitar a continuidade de importações prioritárias e compatíveis com a entrada de poupança externa necessárias; a implementação de barreiras de proteção à indústria doméstica nascente através de um complexo mecanismo de política comercial; o controle da evolução dos preços dos alimentos e, conseqüentemente, do custo de vida via políticas de abastecimento comercial e doméstica de preços; e a institucionalização de um sistema de crédito rural subsidiado, com o intuito de garantir simultaneamente a demanda por insumos industrializados e a modernização e aceleração do crescimento da agricultura brasileira.

A estratégia de crescimento adotada discriminou fortemente a agricultura pelo foco dado exclusivamente nos resultados de eficiência, relegando os efeitos de eqüidade, levando a graves questões estruturais como as disparidades setoriais de distribuição da renda. Segundo Graziano da Silva (1980), esta discriminação se deu pelas próprias políticas adotadas, seguindo princípios da denominada "modernização conservadora", que procuraram elevar a produção através de acréscimos na lucratividade sem aumento nos preços para o consumidor, investindo em comercialização e crédito subsidiado, assim como elevando a produtividade pelo subsídio a insumos modernos e redução da incerteza sobre os preços agrícolas.

No entanto, como discutem os mesmos autores, o impacto da implementação desses incentivos de mercado foi muito limitado em função do interesse do governo em obter resultados imediatos, de curto prazo, com efeitos distributivos perversos. Os setores agrários tradicionais mais fortes e influentes conseguiram se manter no núcleo de poder político do País e pressionaram contra as reformas estruturais necessárias que, se implementadas, os afetariam profundamente. As agriculturas comerciais de escalas grande e média, consideradas capazes de responder mais rápido, e/ou por deterem maior poder junto ao centro de decisões do governo, foram privilegiadas pelas políticas agrícolas do pós-guerra, tendo se beneficiado mais do acesso fácil ao crédito com taxas reais de juros negativas e insumos subsidiados, pela política de preços mínimos e pelos programas de pesquisa e introdução de inovações tecnológicas. No lado oposto, como bem exposto por Lamounier (1994), encontravam-se o pequeno agricultor, o trabalhador rural e as áreas de agricultura tradicional (incluindo agricultores familiares, quilombolas, indígenas, entre outros) à margem do processo de formação e implementação das políticas agrícolas. 
Segundo este autor, durante os anos 80 , houve uma mudança gradual no modelo, passando de distributivo para outro mais regulatório, com impactos mais específicos sobre alguns setores de atividades mais amplos, orientando-se por uma norma geral, reconhecendo a limitação dos recursos. Porém, o governo não conseguiu implementar uma política agrícola coerente devido à pressão e ao descontrole das finanças públicas associadas à aceleração do processo inflacionário. As medidas antiinflacionárias de curto prazo de contenção de gastos públicos, elevação da taxa de juros e medidas heterodoxas atropelaram em vários momentos a política de proteção de renda do setor agrário.

Porém, devido ao processo de democratização e da crise fiscal do estado, as decisões sobre a política agrícola deixaram de ser lideradas pela tecnoburocracia estatal e passaram a contar com a influência de novos setores como o Congresso Nacional, governadores e secretários dos estados, assim como os segmentos agroindustriais e as associações representativas dos produtores rurais. No entanto, os trabalhadores rurais e os pequenos produtores continuaram à margem do processo, de forma que essa modificação também não contribuiu para afetar a grave questão distributiva do Brasil.

A constituição de 1988 pode ser considerada um marco para o setor rural, pois mudou a relação jurídica de direito à propriedade fundiária e, legitimada pela sua função social, universalizou os direitos previdenciários estendidos ao "regime de economia familiar" e reconfigurou o espaço rural sob o influxo dos aposentados rurais, dos assentamentos agrários e dos agricultores familiares em nível significativo do ponto de vista do seu impacto social sobre o setor rural, como discute Delgado (2001). Neder (2001) traz evidências desta discussão, mostrando que um importante componente da renda rural são as aposentadorias que passaram a ter papel relevante como fator distributivo da renda no caso do Brasil rural.

A década de 90 foi marcada pelo plano Real, de estabilização inflacionária, com um crescimento inédito das taxas de desemprego como expõe Gremaldi et al. (2003) e Pinheiro et al. (1999). Seguindo uma receita neoliberal, o País iniciou um processo de abertura comercial e financeira, associado a uma mudança no papel do estado, de empresário para fiscalizador. A abertura do País via quedas nas tarifas de importação e apreciação cambial favoreceu, de início, a expansão do setor de vendas de produtos importados e teve papel fundamental na estabilização dos preços. Porém, não tardou a causar retração na indústria nacional, com a falência de inúmeras empresas brasileiras despreparadas para sobreviver totalmente expostas à competição internacional, somadas à importação de tecnologias mais capital intensivas, alterando a produtividade do trabalho no setor.

Processo semelhante ocorreu na agricultura brasileira, mediado por todo um período de desmonte do aparato de intervenções no setor rural dos períodos anteriores como expõe Delgado (2001). Nestes anos, afirmou-se uma nova 
coalizão distributiva formada por novos grupos financeiros, pelo novo capital estrangeiro atraído pela privatização dos serviços públicos, por exportadores industriais e, sobretudo, pelo agronegócio. A nova política econômica voltada para os interesses dos novos grupos não gerou impulsos expansivos para a economia nacional.

Assim, a estagnação da renda ao longo dos anos 90, decorrente da política de juros altos, dívida crescente e da política fiscal ortodoxa acabou por introduzir um conflito distributivo insanável entre o pagamento dos encargos financeiros da dívida, beneficiando a nova camada de rentistas e as despesas sociais voltadas à transferência de renda. Um conflito direto entre a taxa de juros e o salário mínimo afirmou-se tanto do ponto de vista do gasto público, como do ponto de vista da arrecadação, que cresceu de forma acentuada e regressiva. Isso, por seu turno, bloqueou investimentos necessários em hospitais, educação, saneamento e habitação, ampliando ainda mais os índices de desigualdade e de pobreza, realimentando o processo de estagnação econômica. Segundo o mesmo autor, somente nesta última década houve alguns avanços no campo dos direitos sociais e no Programa de Reforma Agrária, que passou a fazer parte dos programas de governo, porém com aprofundamento da estagnação da indústria e da demanda externa chegando a limites paradoxais.

No governo Lula, o cenário econômico internacional favorável aos preços agrícolas e à diminuição das perdas salariais dos trabalhadores com os reajustes ocorridos no salário mínimo, somados à ampliação de programas de transferência de renda e de crédito subsidiado, como o Fome Zero e o Pronaf, vêm representando um fluxo de renda para as populações rurais mais pobres e pode ter efeito na redução dos índices de concentração de renda e de pobreza do País. Não representa, porém, fator de transformação estrutural das mazelas sociais devido ao caráter assistencialista predominante, não alterando a prioridade à política econômica voltada para os interesses de mercado em detrimento das reformas estruturais necessárias para a erradicação do grave fenômeno da pobreza.

A questão agrária, neste contexto, vai além da evolução dos índices econômicos visto que, com o avanço da estratégia externa da liberalização da economia brasileira, muitas comunidades agrícolas são expulsas de suas terras e reassentadas em locais que não permitem a continuidade de suas atividades produtivas tradicionais e a conseqüente reprodução de seus meios de vida, apesar de serem muitas vezes assistidas pelo programa Bolsa Família, influenciando os dados oficiais disponíveis nas bases estatísticas do governo. A questão é também cultural e política, visto que o modelo neoliberal não resolveu a questão agrária, nem melhorou a situação de pobreza da população rural (MARTINS, 1997), como podem ser confirmados com os resultados do presente estudo. 


\section{Referencial Analítico}

\subsection{Medidas de desigualdade de renda}

A renda pode ser vista como uma distribuição em torno de um valor médio, com variância e assimetria dadas. A curva de Lorenz, como representação da distribuição de renda, é uma associação entre as frações acumuladas da população e as respectivas frações acumuladas da renda total recebida. Na Figura 1 está representada uma distribuição de renda como exemplo. Nos dois casos extremos encontram-se a linha de perfeita igualdade, ou reta de eqüidistribuição, quando todos os indivíduos da população recebem a mesma proporção da renda total, demonstrada no gráfico pela reta pontilhada (AC); e a linha de perfeita desigualdade $(\mathrm{ABC})$, quando apenas um indivíduo recebe toda renda gerada e os outros nada recebem.

Figura 1. Exemplo da curva de Lorenz para uma distribuição de renda dada

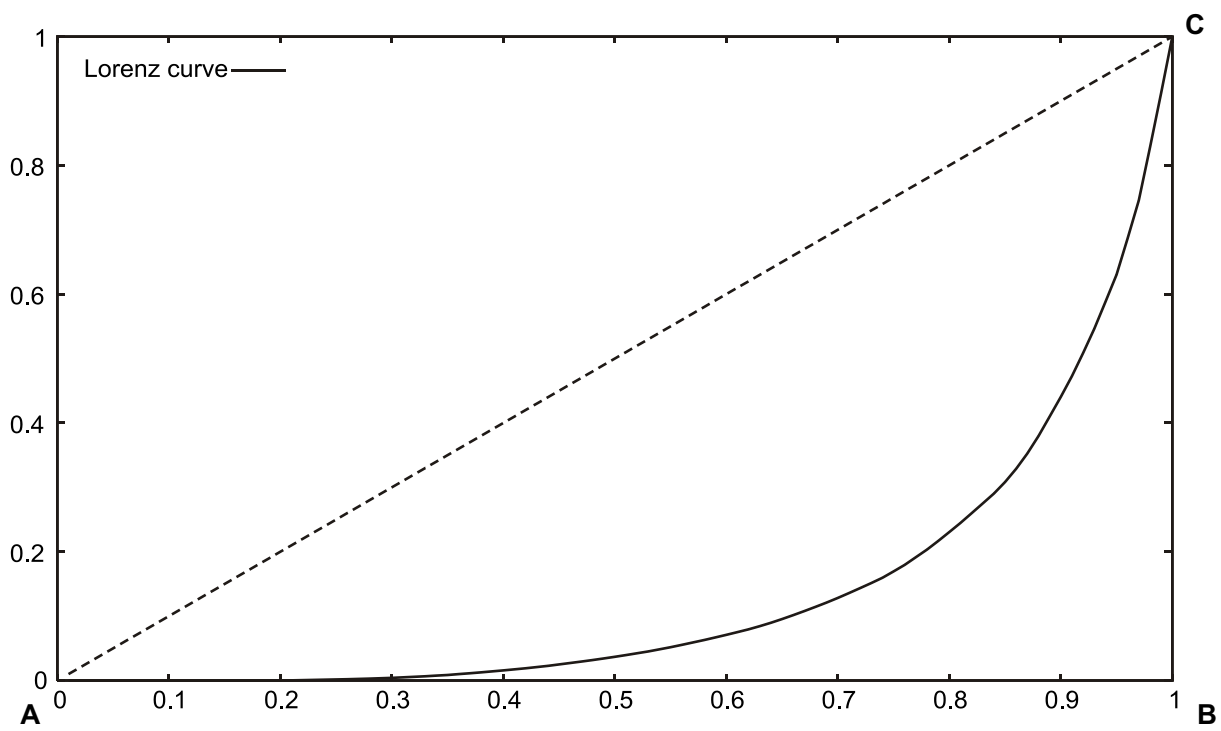

Fonte: Dados da PNAD 2005.

A área entre a reta de eqüidistribuição e a curva de Lorenz mede a desigualdade da distribuição de renda dada. Diferentes índices têm sido usados para medir o grau relativo dessa desigualdade. O índice de Gini, por exemplo, mede a desigualdade relativa da distribuição de renda pela razão entre uma aproximação numérica para a área da desigualdade e a área de uma distribuição de perfeita igualdade (área do triângulo $\mathrm{ABC}$ que é 0,5 ). Essa aproximação pode 
ser realizada por diferentes métodos de integração numérica. Hoffman (1971) traz três a proximações, pela regra do trapézio que aproxima a curva por uma reta, pela regra 1/3 de Simpson usando uma parábola para a aproximação da curva e pela aproximação via função exponencial.

Já a redundância e o índice de Theil (1967) baseiam-se em conceitos da teoria da informação e são dados pelas equações 1 e 2 . Dada uma população com $m$ indivíduos, sendo $p_{1}, p_{2}, \ldots, p_{\mathrm{m}}$ as frações de renda total que cada um recebe, a redundância $(R)$ da distribuição é dada pela Equação 1.

$$
R=\sum_{j=1}^{m} p_{j} \cdot \ln m \cdot p_{j}
$$

No caso de completa igualdade na distribuição da renda, $R=0$, enquanto que, no caso de perfeita desigualdade, $R=\ln m$. Portanto, o valor máximo da redundância depende do número de indivíduos da população. Ao se considerar que nesta população $T$ é a fração da população que nada receberia se a renda fosse igualmente distribuída ao restante $m(1-T)$ de indivíduos, a redundância pode ser então escrita como na Equação 2.

$$
\begin{aligned}
& R=\ln \frac{1}{1-T} \\
& T=1-e^{-R}
\end{aligned}
$$

A fração da população que ficaria sem renda se a renda total fosse igualmente distribuída entre os indivíduos restantes, mantendo-se constante a redundância $R$, resulta no índice $T$ de Theil, apresentando relação direta com a redundância.

Índices de Gini, $T$ de Theil, e $L$ de Theil (a ser definido nos parágrafos seguintes), cujos cálculos são dados por Hoffmann (1971), foram escolhidos para análise, pois obedecem ao critério de Pigou-Dalton, que estabelece que o valor das medidas de desigualdade deve aumentar quando ocorrem transferências regressivas de renda, ou seja, a transferência de renda de um indivíduo para outro mais rico. Ao efetuar esse tipo de transferência, mantendo-se constante a média da distribuição, ocorre conseqüentemente aumento no grau de desigualdade dessa distribuição. Além disso, atendem ao critério da sensibilidade decrescente a transferências, sendo mais sensíveis a transferências de renda na cauda inferior da distribuição do que na superior, e possuem ampla difusão e emprego na literatura, tornando possível a comparação com resultados de outros estudos.

Outra vantagem está na possibilidade de decomposição dos índices $L$ e $T$ de Theil em componentes que dizem respeito às desigualdades entre e intragrupos, quando uma população é dividida em $G$ grupos socioeconômicos de interesse. Assim, um índice de desigualdade decomponível ( $I)$ pode ser genericamente 
indicado pela soma de $I_{e}$, que corresponde à desigualdade obtida caso não existisse desigualdade entre os indivíduos de um mesmo grupo socioeconômico, $\operatorname{com} I_{i}$, que representa a desigualdade dentro dos grupos. A desigualdade total $(I)$ será maior do que $I_{e}$ no montante de $I_{i}$. Portanto, para os índices considerados, esta decomposição segue as funções dadas nas Equações 3 e 4.

$I=I\left(\alpha_{g}, \beta_{g}, I_{g}\right), \operatorname{com} g=1,2, \ldots, G$

onde:

$\alpha_{g}$ é a razão entre a renda média do grupo g e a renda média global

$\alpha_{g}=\frac{\bar{X}_{g}}{\mu}$

$\beta_{g}$ é a proporção da população ocupada no grupo $g$

$\beta_{g}=\frac{n_{g}}{N}$

$I_{g}$ é a desigualdade dos rendimentos dos indivíduos do g-ésimo grupo

$R=\sum_{g} \alpha_{g} \cdot \beta_{g} \cdot \ln \alpha_{g}+\sum_{g} \alpha_{g} \cdot \beta_{g} \cdot R_{g}$

onde $R_{g}$ é a redundância do grupo $g$

$L=-\sum_{g} \beta_{g} \cdot \ln \alpha_{g}+\sum_{g} \beta_{g} \cdot L_{g}$

onde $L_{g}$ é o índice $L$ do grupo $g$

O primeiro termo das equações representa a desigualdade entre grupos, enquanto o segundo a desigualdade no interior de cada grupo. Ambos os termos são médias ponderadas, sendo o primeiro a média dos logaritmos da razão entre a renda média de cada grupo e a renda média da população, enquanto que o segundo é a média ponderada das desigualdades internas. Os pesos são as proporções da renda total em poder de cada grupo. Para o $L$ de Theil tem-se também uma média ponderada, porém, agora os pesos são as frações populacionais de cada grupo.

\subsection{Medidas de Pobreza}

A definição de pobreza nos trabalhos científicos da área associa-se à insuficiência de renda, ou seja, à pessoa possuir uma renda média inferior a uma linha de pobreza $(L P)$ previamente estabelecida. Os critérios de definição da $L P$ são diversificados entre os autores, alguns trabalham com o valor de US\$1 ou US $\$ 2$ por dia, enquanto outros preferem a referência de $1 / 2$, um ou dois salários 
mínimos, podendo também ser determinada pela renda mínima suficiente para adquirir os bens necessários à sobrevivência ou para a aquisição de uma cesta de bens de primeira necessidade. Neste trabalho, optou-se por considerar o valor de meio salário mínimo de 1980, deflacionado pelo INPC, como linha de pobreza como sugerido por Corrêa (1998) e Hoffmann (1995) para manter a LP constante no tempo, além de ser útil para comparar resultados.

Definida a linha de pobreza, a medida de pobreza pode ser definida como sugerem Marinho \& Soares (2003) pela proporção da população que vive na situação de pobreza, pelos índices de Foster-Greer-Thorbecke (FGT) que podem ser formalmente definidos como na Equação 5. A primeira medida, de incidência de pobreza, é a razão entre os números de indivíduos vivendo abaixo da $L P$ e a população total. A segunda, medida de insuficiência média da renda, quanto maior, menor é a renda média dos pobres em relação à $L P$. E a terceira é a medida da desigualdade entre os indivíduos que vivem em condição de pobreza.

$$
\begin{aligned}
& P_{0}=\frac{q}{n} \text { medida da incidência de pobreza } \\
& P_{1}=\frac{1}{n} \sum_{i=1}^{q} \frac{L P-y_{i}}{L P} \text { medida de insuficiência média de renda } \\
& P_{2}=\frac{1}{n} \sum_{i=1}^{q}\left(\frac{L P-y_{i}}{L P}\right)^{2} \text { medida da desigualdade entre os pobres }
\end{aligned}
$$

Sendo $q$ o número de pobres, $n$ é o tamanho da população e $y_{i}$ a renda per capita domiciliar da $i$-ésima pessoa. Os três índices em conjunto se complementam mutuamente na compreensão do fenômeno da pobreza. $\mathrm{O}$ primeiro $\left(P_{0}\right)$ é usado como ponto de partida para estudos da pobreza, porém, viola dois axiomas importante: o de não se alterar quando a renda se eleva sem alcançar a $L P$ e o de ser insensível a alterações na distribuição de renda entre os pobres. O segundo calcula o desvio médio entre a renda dos pobres e o valor da linha de pobreza, podendo ser interpretado como indicador dos recursos necessários para elevar a renda de todos os pobres ao nível da $L P$ através de uma perfeita focalização das transferências de renda, seria o hiato da pobreza. Enquanto que o terceiro, o hiato da pobreza ao quadrado pode ser usado como um indicador da severidade da pobreza. Como houve perdas salariais por todos os anos estudados com relação à base de salário mínimo de 1980, calculou-se o número proporcional de pessoas com renda no nível de $1 / 2$ a 1 salário mínimo abaixo da $L P$ por interpolação linear. 


\subsection{Determinação da Elasticidade da Pobreza}

O conceito de elasticidade da pobreza mede as variaçóes percentuais de indicadores de pobreza associadas a variaçóes percentuais da renda média de uma determinada população ou a variações dos índices de concentração. Considerando-se a renda média, uma elasticidade igual a um indica que, para a variação de $1 \%$ sobre a renda média, ceteris paribus, haverá, em média, uma variação na mesma proporção (1 ponto percentual) sobre o índice de pobreza escolhido. Caso a elasticidade seja menor que um, esta variação percentual será menos que proporcional, enquanto que, para uma elasticidade maior que um, será mais que proporcional. Esperam-se que as elasticidades da pobreza com relação ao índice de concentração de renda sejam positivas, ou seja, que o aumento percentual sobre a concentração da renda leve ao aumento percentual nos índices de pobreza. Por outro lado, esperam-se sinais negativos para as elasticidades com relação ao crescimento da renda média, associando a este reduções percentuais nos índices de pobreza.

Optou-se pela metodologia proposta por Datt (1998), na qual o cálculo dos valores das elasticidades se dá a partir de dados de distribuição de renda agrupados, considerando a especificação Quadrática Geral para a curva de Lorenz apresentada na Equação 6. Lz é a participação dos p por cento mais pobres da população na renda per capta domiciliar, $\pi$ é um vetor de parâmetros estimáveis da curva de Lorenz, $P$ é a medida de pobreza escrita como função da relação da renda per capita domiciliar média $\mu$ e a linha de pobreza $(L P)$ e os parâmetros da curva de Lorenz, $H$ é a proporção de pobres, $H P$ é o hiato da pobreza, $P_{2}$ é a severidade da pobreza da classe dos índices FGT de pobreza e os parâmetros $e, m, n, r, s_{1}$ e $s_{2}$ são dados na Equação 7 .

$$
\begin{aligned}
& L z=L z(p ; \pi) \quad \text { Curva de Lorenz } \\
& \left.\begin{array}{l}
P=P(\mu / L P ; \pi) \quad \text { Dedida de pobreza } \\
L z(1-L z)=a \cdot\left(p^{2}-L z\right)+b \cdot L z \cdot(p-1)+c \cdot(p-L z) \\
\left.\begin{array}{l}
L z(1-L z)=-\frac{1}{2 \cdot m}\left[b \cdot p+e+\left(m \cdot p^{2}+n \cdot p+e^{2}\right)^{1 / 2}\right]
\end{array}\right\} \begin{array}{l}
\text { Especificação } \\
\text { Quadrática Geral }
\end{array} \\
\begin{array}{l}
H=-\frac{1}{2 \cdot m}\left[n+r \cdot(b+2 \cdot L P / \mu) \cdot\left\{(b+2 \cdot L P / \mu)^{2}-m\right)^{-1 / 2}\right] \\
H P=H-(\mu / L P) \cdot L z(H)
\end{array} \\
P_{2}=2(H P)-H-\left(\frac{\mu}{L P}\right)^{2}\left[a \cdot H+b \cdot L z(H)-\left(\frac{r}{16}\right) \cdot \ln \left(\frac{1-H / s_{1}}{1-H / s_{1}}\right)\right]
\end{array}\right\} \begin{array}{l}
\text { Medidas } \\
\text { de Pobreza }
\end{array}
\end{aligned}
$$




$$
\begin{aligned}
& e=-(a+b+c+1) \\
& m=b^{2}-4 \cdot a \\
& n=2 \cdot b \cdot e-4 \cdot c \\
& r=\left(n^{2}-4 \cdot m \cdot e^{2}\right)^{1 / 2} \\
& s_{1}=(r-n) /(2 \cdot m) \\
& s_{2}=-(r+n) /(2 \cdot m)
\end{aligned}
$$

Para a obtenção dos parâmetros $a, b$ e $c$ da curva de Lorenz foram realizadas regressões lineares para os anos de 2001, 2003 e 2005 pelo Método dos Quadrados Mínimos de $L z(1-L z)$ contra $\left(p^{2}-L z\right), L z .(p-1)$ e $(p-L z)$. Os valores das elasticidades da pobreza em relação à renda média e ao índice de Gini $(G)$ foram calculados pelas funções dadas na Equação 8.

\subsection{Base de Dados}

Foi usada como base de dados as Pesquisas Nacionais por Amostra de Domicílios (PNAD) entre 1995 e 2005. Embora forneçam informações necessárias, ressaltam-se algumas limitações que precisam ser levadas em consideração na análise dos resultados. Refletem rendas monetárias e pagamentos em espécie, não considerando a produção para autoconsumo, que muitas vezes ainda representa parte importante da renda real dos pequenos agricultores e trabalhadores rurais, apesar da depredação social e ambiental provocada pela "agricultura moderna" que vem acabando com essa fonte de renda, aproximando o homem rural do homem urbano em termos de dependência de renda monetária.

$$
\begin{aligned}
\varepsilon_{H, \mu} & =-\frac{L P}{\mu \cdot H \cdot L^{\prime \prime}(H)} \\
\varepsilon_{H, G} & =-\frac{1-L P / \mu}{H \cdot L^{\prime \prime}(H)} \\
\varepsilon_{H P, \mu} & =1-\frac{H}{H P} \\
\varepsilon_{H P, G} & =1+\frac{(\mu / L P-1) \cdot H}{H P} \\
\varepsilon_{P_{2}, \mu} & =2 \cdot\left(1-H P / P_{2}\right) \\
\varepsilon_{P_{2}, G} & =2 \cdot\left[1+(\mu / L P-1) \cdot H P / P_{2}\right] \\
L^{\prime \prime}(H) & =\frac{r^{2} \cdot\left(m \cdot H^{2}+n \cdot p+e^{2}\right)^{-3 / 2}}{8}
\end{aligned}
$$


É uma série de cortes transversais que contêm um mesmo conjunto de informações, sendo possível inferir sobre a proporção de trabalhadores com o mesmo conjunto de atributos e características em diferentes momentos de tempo, mas não acompanham o mesmo grupo de indivíduos ao longo do tempo. A subdeclaração dos rendimentos mais elevados leva a uma subestimativa do grau de desigualdade da distribuição de renda e da pobreza. Aspectos ligados à metodologia de coleta de dados também podem levar a uma subestimativa da renda total declarada pelos indivíduos entrevistados. Para o caso da população rural, exclui a área rural da região Norte, importante área onde se estende a fronteira agrícola do País. Por ter como base uma semana específica de referência não permite que se capte a variabilidade das atividades agrícolas no País ao longo do ano.

\subsection{Operacionalização}

A escolha da unidade de análise levou em conta a população acima de 10 anos residente em áreas rurais por considerar que, devido às características específicas da agricultura tradicional e familiar, que ocupa a maioria da população rural, a população não economicamente ativa também é representativa na geração da renda, assim como dos gastos, como é o caso das aposentadorias rurais. $\mathrm{O}$ período estudado, de 1995 a 2005, foi escolhido por ser pós-implementação do plano Real, considerado um período sem grandes mudanças na política econômica. Em 2000 não havia informações disponíveis devido à realização do censo neste ano, em detrimento da PNAD, sendo desprezado no estudo.

A variável a ser estudada foi definida como sendo o valor do rendimento mensal médio. Limitou-se o universo de análise dos indivíduos com renda de todos os trabalhos positiva para o cálculo do índice de Theil por trabalharem com logaritmos da renda. Mas optou-se por incluir estas informações em todos os outros cálculos por serem consideradas parte relevante na compreensão da distribuição de renda e do fenômeno da pobreza nas áreas rurais.

Usou-se, também, os dados agrupados por nível de renda, sendo que foram considerados os níveis de renda de até $1 / 2$ salário mínimo (SM), de $1 / 2$ a $1 \mathrm{SM}$, de 1 a 2 SMs, de 2 a 3 SMs, de 3 a 5 SMs, de 5 a 10 SMs, de 10 a 20 SMs, mais de 20 SMs. Assim, de posse sobre a renda média e o número de indivíduos de cada grupo ao longo do tempo, as equações foram aplicadas considerando a distribuição de igualdade perfeita dentro de cada grupo. Foi empregado para a geração das estimativas estatísticas o software livre Gretl (2007) e os dados públicos disponibilizados pelo IBGE em http://www.ibge.gov.br/home/\#sub_download. 


\section{Resultados e Discussões}

\subsection{Curvas de Lorenz, Índices de Gini e de Theil}

A evolução das curvas de Lorenz para todo o período pode ser vista na Figura 2. Como as curvas se interceptam, graficamente a análise de dominância fica prejudicada. Percebe-se que a forma da curva também muda ao longo do tempo, tornando-se menos inclinada com relação ao eixo das abscissas para a população de menor renda e mais inclinada para a de maior renda. Associa-se a esta quebra estrutural uma perda de renda da população mais pobre situada no lado da cauda esquerda para a população mais rica, do lado da cauda direita, entre 1998 e 2001, representando uma mudança na estrutura da concentração de renda no meio rural.

Para mais de $60 \%$ da população rural situada do lado da cauda esquerda, piorou a distribuição da renda, cuja soma total representa menos que $15 \%$ da renda total. Esta constatação de concentração de renda entre os mais pobres teve como contexto político-econômico a adoção do modelo neoliberal em concordância com instituições internacionais entre as quais um dos maiores representantes é o Fundo Monetário Internacional (FMI). A verificação do ponto de mudança nos coeficientes da relação após 1998 coincide com a defasagem observada em outros reflexos às mudanças relativas à política econômica efetuadas nos primeiros anos da década, tais como a abertura econômica, as privatizações, entre outras medidas liberalizantes.

Figura 2. Curvas de Lorenz para cada ano do período de 1995 a 2005

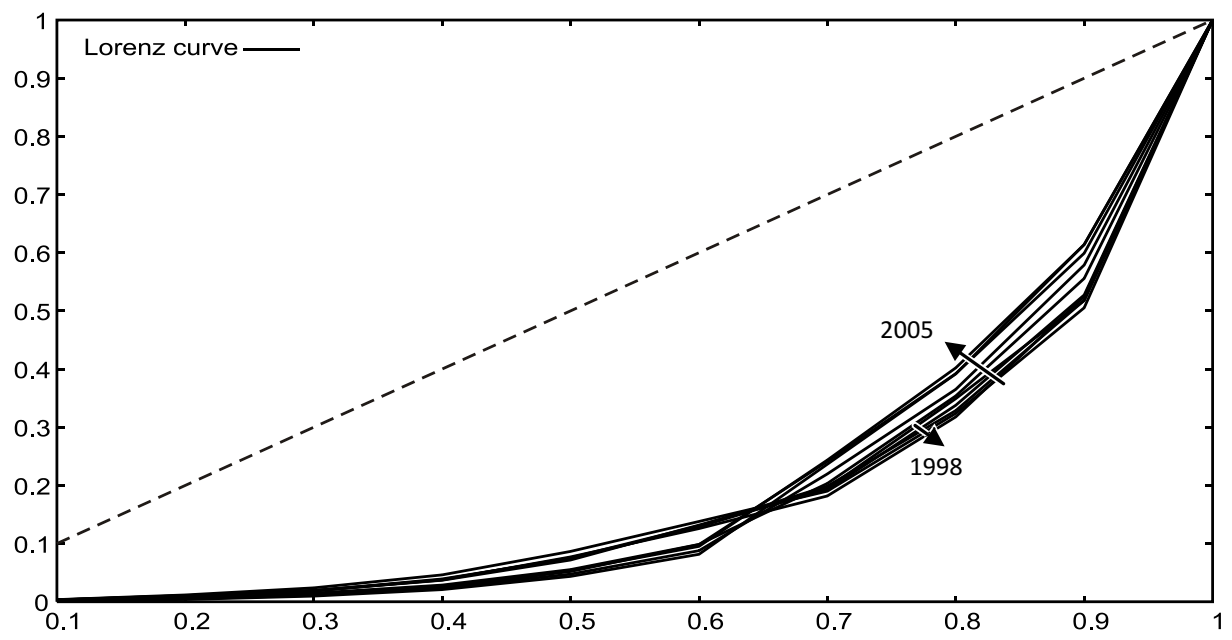

Fonte de dados: Resultados da pesquisa. 
Um exemplo de reflexo observado concomitantemente vem do setor industrial, para o qual o ano de 1997 foi marcado no Brasil por uma forte crise de empregos, a partir de quando Pinheiro et al. (1999) descrevem uma mudança de preocupação com a qualidade para a quantidade de emprego. A crise econômica também se estendeu ao setor rural, no entanto, se fez sentir mais acentuadamente pela população mais pobre, representando mais de $60 \%$ dos indivíduos. Enquanto isso, o restante da população, detentora da maior parcela da renda, melhorou a distribuição da mesma, mas apenas entre os indivíduos do mesmo grupo de renda.

Percebem-se claramente dois períodos distintos da forma de distribuição de renda no País, um antes de 1998, havendo dominação estrita da curva de Lorenz de 1998 sobre a de 1995, representando um aumento na concentração da distribuição de renda, e outro depois, com dominação estrita da curva de Lorenz de 2001 sobre a de 2005, representando uma redução na concentração da renda, não significativa o suficiente para alterar a estrutura das distribuições acumuladas que permanecem desfavoráveis para a população de menor renda. Estes movimentos separados podem ser visualizados nas Figuras 3 e 4 .

Figura 3. Movimento da Curva de Lorenz de 1995 a 1998

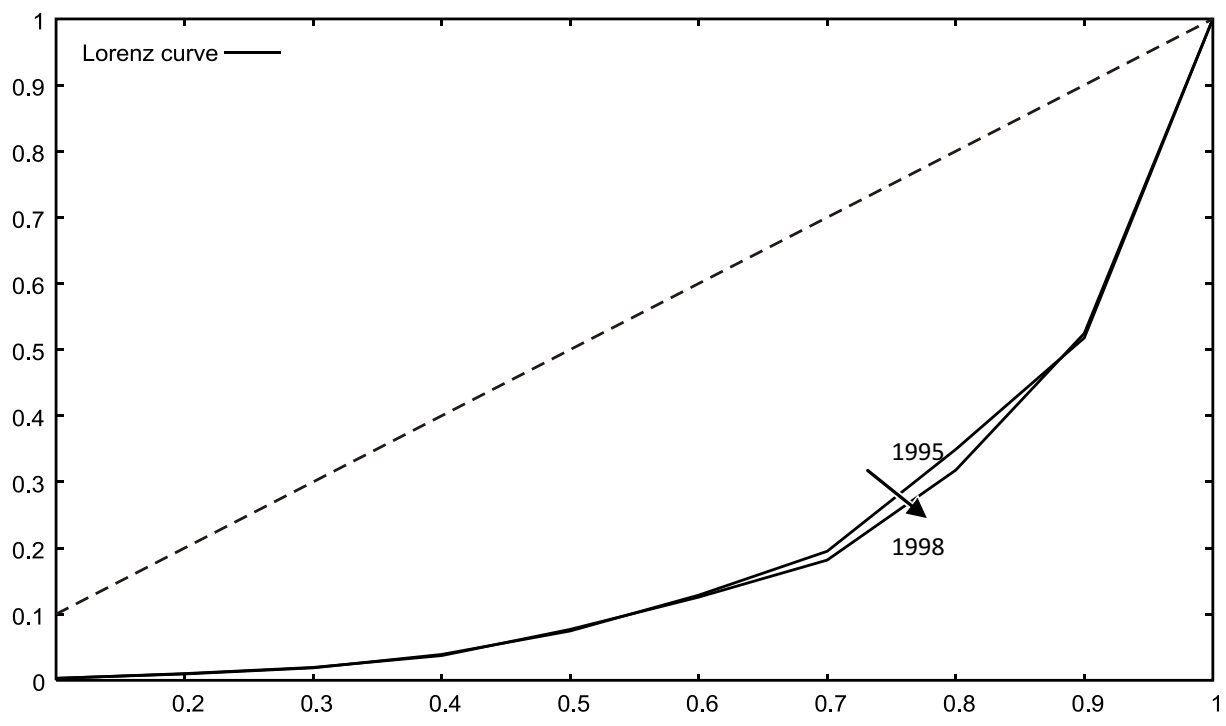

Fonte de dados: Resultados da pesquisa. 
Figura 4. Movimento da Curva de Lorenz de 2001 a 2005

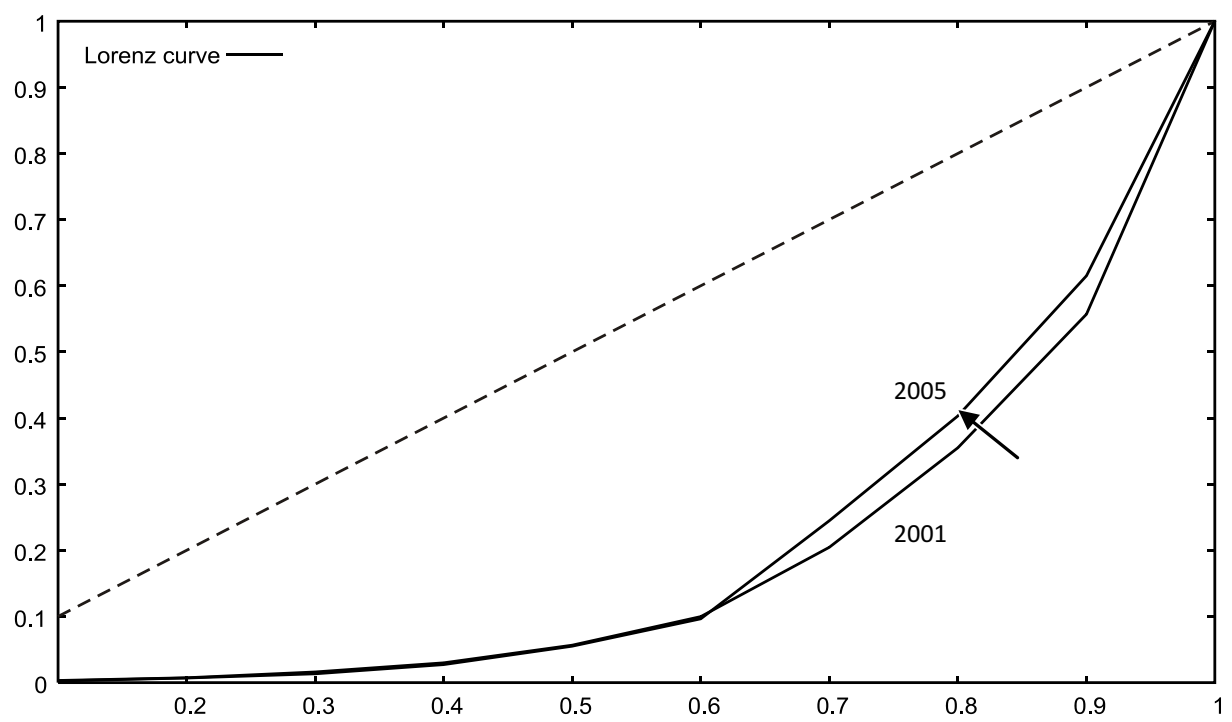

Fonte de dados: Resultados da pesquisa.

Os coeficientes de Gini estimados para cada ano, incluindo pessoas sem rendimentos e sem declaração, estão na Tabela 1 junto com os índices de redundância $R, L$ e $T$ de Theil calculados.

Tabela 1. Índices de Gini $(G)$ e de Theil para o meio rural do Brasil

\begin{tabular}{ccccc}
\hline Ano\Índice & $\boldsymbol{G}$ & $\boldsymbol{R}$ & $\boldsymbol{L}$ & $\boldsymbol{T}$ \\
\hline 1995 & 0,6328 & 1,2227 & $-0,1208$ & 0,7056 \\
1996 & 0,6343 & 1,2473 & $-0,1322$ & 0,7127 \\
1997 & 0,6356 & 1,0138 & $-0,0804$ & 0,6372 \\
1998 & 0,6406 & 1,2158 & $-0,1131$ & 0,7035 \\
1999 & 0,6339 & 0,9903 & $-0,0925$ & 0,6285 \\
2001 & 0,6364 & 1,1153 & $-0,0975$ & 0,6722 \\
2002 & 0,632 & 1,0401 & $-0,0756$ & 0,6466 \\
2003 & 0,6147 & 1,0737 & $-0,0239$ & 0,6583 \\
2004 & 0,6672 & 1,0351 & $-0,0344$ & 0,6448 \\
2005 & 0,6193 & 0,9827 & $-0,0569$ & 0,6257 \\
\hline
\end{tabular}

Fonte: Resultados da pesquisa.

Pelos índices de Gini, para cada ano, percebe-se que existe uma tendência crescente entre 1995 e 1999. Neste ano há uma queda no índice, seguida de um aumento no ano de 2001. A partir daí, a tendência é decrescente, exceto para o 
penúltimo ano do período (2004), cujo índice apresenta um elevado aumento com relação aos anos anteriores, voltando a cair no ano seguinte, porém, em proporção menor que o aumento ocorrido no ano anterior.

Quanto mais próximo estes valores estiverem de zero, mais próxima a distribuição da renda se encontra da perfeita igualdade. Neste sentido, o valor mais baixo encontrado para oíndice $R$ foi para o ano de 2005, enquanto que para o índice $L$ foi o ano de 2003, confirmando o comportamento verificado no índice de Gini. Os valores estão próximos, em média, aos encontrados para os estados por Marinho \& Soares (2003), apesar de serem sempre superiores, o que pode se associar a estes não terem se restringido ao meio rural, além de não captarem as interações entre estados.

Assim como também se aproximam dos valores obtidos para o meio rural por Neder \& Mariano da Silva (2003), apesar de também serem maiores, o que pode estar relacionado com as particularidades consideradas na seleção das amostras. Vale ressaltar que para o cálculo dos índices de Theil não foram consideradas as pessoas com mais de 10 anos com rendimentos nulos e sem declaração, o que estaria subestimando a desigualdade real. Porém, a evolução destes está de acordo com a do índice de Gini.

A diferença no comportamento de $R$ e $L$ deve-se aos diferentes pesos considerados nos cálculos, sendo no primeiro a renda total em poder de cada grupo de renda e, no segundo, as frações populacionais em cada grupo de renda. Podem-se perceber os elevados valores dos índices $T$ de Theil, atingindo um valor mínimo no ano de 2005 de 0,6257, significando que, em média, 63\% desta população ficaria sem renda caso esta fosse igualmente distribuída entre os indivíduos restantes, mantendo constante a redundância $(R)$.

\subsection{Os índices de pobreza para $o$ setor rural brasileiro de 1995 a 2005}

Os valores da LP para o período de 1995 a 2005 estão dispostos na Tabela 2 e foram calculados considerando o valor de 1/2 salário mínimo de agosto de 1980, deflacionado pelo INPC para os meses de setembro de cada ano. O valor de $1 / 2$ salário mínimo vigente em todos os anos também foi apresentado no intuito de visualizar as perdas salariais ocorridas com relação a 1980.

Tabela 2. Linha de Pobreza (LP) e 1/2 Salário Mínimo (SM) vigente em reais para os anos de 1995 a 2005

\begin{tabular}{cccccccccccc}
\hline Ano & $\mathbf{1 9 9 5}$ & $\mathbf{1 9 9 6}$ & $\mathbf{1 9 9 7}$ & $\mathbf{1 9 9 8}$ & $\mathbf{1 9 9 9}$ & $\mathbf{2 0 0 0}$ & $\mathbf{2 0 0 1}$ & $\mathbf{2 0 0 2}$ & $\mathbf{2 0 0 3}$ & $\mathbf{2 0 0 4}$ & $\mathbf{2 0 0 5}$ \\
\hline LP & 71,37 & 80,63 & 84,41 & 87,08 & 92,29 & 98,75 & 105,98 & 116,14 & 136,47 & 144,60 & 151,82 \\
SM & 50,00 & 56,00 & 60,00 & 65,00 & 68,00 & 75,50 & 90,00 & 100,00 & 120,00 & 130,00 & 150,00 \\
$\Delta$ & 21,37 & 24,63 & 24,41 & 22,08 & 24,29 & 23,25 & 15,98 & 16,14 & 16,47 & 14,60 & 1,82 \\
\hline
\end{tabular}

Fonte: LP: resultados da pesquisa; SM: sítio do Ministério do Trabalho e Emprego - MTE (2010). 
Percebe-se que houve uma redução das perdas salariais com relação ao salário mínimo de agosto de 1980, sendo que no ano de 2005 os valores quase se equipararam. Este fato pode estar associado à redução das desigualdades na distribuição da renda rural observadas de 2001 a 2005.

O cálculo dos índices e elasticidades da pobreza deu-se via regressão linear de mínimos quadrados ordinários (MQO) de $L z(1-L z)$ contra $\left(p^{2}-L z\right),(p-1)$ e $(p-L z)$, lembrando que $L z$ é a função quadrática de aproximação para a curva de Lorenz e $p$ é a proporção mais pobre da população ordenada pela renda. Restringiu-se ao segundo movimento e estrutura da distribuição de renda observados no período, incluindo os anos mais recentes de 2001, 2003 e 2005 para obtenção dos $(a, b, c)$ 's para cada ano, o que facilitou a comparação dos resultados com outros autores. Os resultados gerados estão dispostos nas Tabelas 3,4 e 5 .

Tabela 3. Índices e elasticidade pobreza para o Brasil para o ano de 2001

\begin{tabular}{ccccc}
\hline Variável & Coeficiente & Erro padrão & Estatística-t & valor-p \\
\hline Const & 0,0048 & 0,0169 & 0,2842 & 0,7858 \\
$(p 2-L)$ & 0,3639 & 0,4265 & 0,8533 & 0,4263 \\
$(p-1)$ & $0,5810^{* * *}$ & 0,1513 & 3,8389 & 0,0086 \\
$(p-L)$ & 0,5190 & 0,3450 & 1,5044 & 0,1832 \\
\hline Regressando & Média: & 0,1159 & Desv. Pad.: & 0,0991 \\
Resíduos & SQR: & 0,0024 & Desv. Pad.: & 0,0201 \\
$R^{2}$ & 0,9727 & $R^{2}$ ajustado & 0,9590 & \\
Estatística F $(3,6)$ & 71,1287 & p-value & $4,43 \mathrm{e}-5$ & \\
\hline
\end{tabular}

Fonte de Dados: Resultados da Pesquisa; ${ }^{* * *}$ significativo a um nível de $1 \%$.

Tabela 4. Índices e elasticidade pobreza para o Brasil para o ano de 2003

\begin{tabular}{ccccc}
\hline Variável & Coeficiente & Erro padrão & Estatística-t & Valor-p \\
\hline Const & 0,0023 & 0,0208 & 0,1122 & 0,9143 \\
$(p 2-L)$ & 0,7407 & 0,5009 & 1,4786 & 0,1897 \\
$(p-1)$ & $0,3615^{*}$ & 0,1576 & 2,2947 & 0,0616 \\
$(p-L)$ & 0,2026 & 0,3889 & 0,5210 & 0,6210 \\
\hline Regressando & Média: & 0,1126 & Desv. Pad.: & 0,0995 \\
Resíduos & SQR: & 0,0042 & Desv. Pad.: & 0,0264 \\
$R^{2}$ & 0,9532 & $R^{2}$ ajustado & 0,9297 & \\
Estatística F $(3,6)$ & 40,6963 & p-value & 0,0002 & \\
\hline
\end{tabular}

Fonte de Dados: Resultados da Pesquisa; * significativo a um nível de $10 \%$. 
Tabela 5. Índices e elasticidade pobreza para o Brasil para o ano de 2005

\begin{tabular}{ccccc}
\hline Variável & Coeficiente & Erropadrão & Estatística-t & Valor-p \\
\hline Const & $0,2414^{* * *}$ & 0,0589992 & 4,0912 & 0,0064 \\
$(\mathrm{p} 2-\mathrm{L})$ & 0,5216 & 0,602194 & 0,8661 & 0,4197 \\
$(\mathrm{p}-1)$ & $0,7167^{* * *}$ & 0,0918072 & 7,8063 & 0,0002 \\
$(\mathrm{p}-\mathrm{L})$ & 0,4502 & 0,476081 & 0,9457 & 0,3808 \\
\hline Regressando & Média: & 0,107365 & Desv. Pad.: & 0,0947 \\
Resíduos & SQR: & 0,003942 & Desv. Pad.: & 0,0256 \\
$\mathrm{R}^{2}$ & 0,9511 & $\mathrm{R}^{2}$ ajustado & 0,9267 & \\
Estatística F $(3,6)$ & 38,9126 & p-value & 0,0003 & \\
\hline
\end{tabular}

Fonte de Dados: Resultados da Pesquisa; ${ }^{* * *}$ significativo a um nível de $1 \%$.

Nas equações que representam os anos de 2001 e 2003 não foram detectados problemas de heterocedasticidade, porém, os termos de erro não seguem uma distribuição normal, o que sugere cautela ao analisar os resultados dos testes de hipóteses. Mas os estimadores de Mínimos Quadrados Ordinários (MQO) permanecem consistentes e não tendenciosos, apesar da quebra deste pressuposto. Os valores dos termos constantes foram muito baixos, além de não significativos ao nível de $10 \%$.

Para o ano de 2005, ao tratar o problema apresentado de heterocedasticidade pela correção de White na regressão com o termo constante, chegou-se a raiz de um número negativo. Retirando-se a constante deste modelo, os coeficientes encontrados ficaram fora do intervalo de confiança, além de contradizerem as expectativas dadas pela Equação 6. Além dos outros problemas relacionados a regressões sem o termo constante, estas observações levaram à opção pelo método de mínimos quadrados ordinários simples, com os termos de intercepto. O cálculo dos índices de pobreza pela substituição dos valores de (a, b, c) obtidos nas regressões na Equação 6 estão na Tabela 6.

Quando se comparam os índices calculados pelo método de DATT (1998) para os três anos, percebe-se que, apesar da proporção de pobres $(\mathrm{H})$ ter diminuído, acompanhando o comportamento dos índices de desigualdade, os índices associados à insuficiência de renda (HP) e à severidade da pobreza (P2) aumentaram. Ou seja, os recursos necessários para elevar a renda de todos os pobres ao nível da linha de pobreza para 2003 seriam maiores que os para o 2001, apesar deste ano apresentar a maior proporção da população abaixo da LP. Isto concorda também com a verificação gráfica de concentração de renda entre os mais pobres, diminuindo a proporção de indivíduos com renda abaixo da LP, porém, pela transferência de renda dos indivíduos que permaneceram na situação de pobreza, reforçando o processo histórico de concentração de renda da economia rural brasileira. 
Tabela 6. Índices de pobreza e suas elasticidades de Datt (Eq. 6) e de FGT (Eq.5)

\begin{tabular}{ccccccc}
\hline Índice & 2001(Eq.6) & 2003(Eq.6) & 2005(Eq.6) & 2001(Eq.5) & 2003(Eq.5) & 2005(Eq.5) \\
\hline$H$ & 0,6132 & 0,5827 & 0,5848 & 0,5936 & 0,5868 & 0,5496 \\
$H P$ & 0,2879 & 0,4713 & 0,3373 & 0,5100 & 0,4981 & 0,4672 \\
$P 2$ & 0,2205 & 0,6389 & 0,3815 & 0,4813 & 0,4599 & 0,4283 \\
$e(H / r m)$ & $-0,7348$ & $-0,6839$ & $-0,7258$ & - & - & - \\
$E(h p / r m)$ & $-1,1298$ & $-0,2363$ & $-0,7338$ & - & - & - \\
$E(p 2 / r m)$ & $-0,6108$ & 0,4942 & 0,2317 & - & - & - \\
$e(H / g)$ & 0,3398 & 0,3425 & 0,3736 & - & - & - \\
$e(h p / g)$ & 1,9850 & 1,6191 & 1,8926 & - & - & - \\
$e(p 2 / g)$ & 3,2075 & 2,7389 & 2,9102 & - & - & - \\
\hline
\end{tabular}

Fonte: Resultados da pesquisa.

Portanto, o primeiro índice atribui maior efetividade às políticas que elevam a renda dos menos pobres, mas não é sensível às transferências de renda de uma pessoa mais pobre para outra cuja renda esteja mais próxima da linha de pobreza. Por outro lado, os outros dois colocam ênfase nos que estão muito abaixo da linha de pobreza, associando-se à distribuição de renda entre os pobres.

Com relação aos índices de Foster-Greer-Thorbecke calculados e também expostos na Tabela 6 (Eq. 5), percebe-se que apenas os valores de $\mathrm{H}$ foram próximos, enquanto que os outros dois ou foram subestimados ou superestimados com relação aos primeiros. A relação apresentou-se sempre decrescente por este método para os três índices de pobreza sendo, portanto, o primeiro mais sensível aos movimentos observados pela evolução das curvas de Lorenz. A consideração agregada de dados pode estar contribuindo significativamente para esta diferença tendo maior efeito sobre os índices de FGT, mascarando este comportamento.

Comparando os resultados com a análise por estados realizada por Neder et al. (2003), percebeu-se que os valores foram próximos, apesar de novamente sempre superiores aos obtidos para todos os estados brasileiros. Isto pode também estar associado à forma agregada de dados usada no presente trabalho, além de poder estar captando não só as desigualdades intra-estados, mas também as entre-estados.

Quanto à interpretação das elasticidades, verifica-se que apresentaram os sinais esperados, com exceção do índice P2 para os anos de 2003 e 2005, o que pode ter sido influenciado pela aproximação quadrática da curva de Lorenz. Para o ano de 2001, um aumento de $1 \%$ na renda média, ceteris paribus, levaria a uma redução em média de 0,73 na proporção de pobres, de 1,13 no índice de 
insuficiência de renda relativa à LP, e de 0,61 no índice sensível à severidade da pobreza no mesmo ano. Por outro lado, o aumento de $1 \%$ na concentração de renda deste ano, ceteris paribus, levaria a um aumento, em média, de 0,33 no índice de proporção de pobres, de 1,99 no de insuficiência de renda relativa à LP e de 3,21 no índice sensível à severidade da pobreza no mesmo ano. A mesma análise pode ser feita para os outros anos.

Como as elasticidades da pobreza com relação ao índice de Gini foram maiores que as elasticidades em relação ao crescimento da renda média para os dois últimos índices, o efeito isolado de uma desconcentração da renda seria maior junto às populações mais pobres, atuando com maior significância nos índices associados à intensidade e severidade da pobreza. Por outro lado, o efeito isolado de um crescimento da renda média seria maior junto à proporção de pobres com renda próxima à da LP, sendo mais significativo na alteração do primeiro índice de pobreza. Neste caso, apesar de diminuir a fração da população abaixo da LP, a severidade da pobreza remanescente não teria melhorias tão significativas quanto às de uma desconcentração de renda.

Este resultado coincide com o obtido por Neder et al. (2003) para áreas rurais com os dados da PNAD de 2001 desagregados por estados brasileiros, cujas elasticidades dos índices de pobreza com relação à renda média foram maiores para o primeiro índice em todos os estados (exceto para os estados das regióes sudeste, sul e centro-oeste) do que as elasticidades com relação à distribuição de renda, e menores que estas para os outros dois índices sem exceção. Os valores foram muito próximos, com exceção dos estados das regiões sudeste, sul e centro-oeste que apresentaram elasticidades com relação à distribuição de renda bem superiores às elasticidades com relação ao crescimento da renda média, e as dos estados das regióes norte e nordeste. Vale ressaltar que os maiores índices de pobreza estão associados a estas duas regióes concordando com a teoria que espera a obtenção de menores elasticidades para as regiões mais pobres.

Com relação aos valores obtidos por Hoffmann (2005) para o Brasil, incluindo também as regiões urbanas, os índices de pobreza obtidos foram maiores, associando uma maior pobreza às áreas rurais quando comparadas às áreas urbanas. Além das diferenças inerentes às duas metodologias que, entre outras, o autor considerou uma aproximação log-normal para a distribuição de renda em vez da aproximação quadrática. A exclusão das populações sem renda para poder trabalhar com a função logarítmica pode ter também subestimado a dimensão da pobreza nos demais estudos. Já as elasticidades obtidas foram menores, confirmando menores elasticidades a maiores concentrações da distribuição de renda e a menores rendas médias esperadas pela teoria. 


\section{Conclusões}

Os resultados mostraram que o processo de desconcentração de renda no meio rural brasileiro de 2001 a 2005 não foi significativo o suficiente para alterar o processo histórico concentrador de renda e de pobreza no setor. As proporções de pobres para todos os anos e pelos dois métodos empregados ficaram acima dos $50 \%$ da população rural total acima de 10 anos, sendo que houve ainda uma perda de renda por esta parcela da população. O ano de 1998 marcou esta perda pela mudança verificada na estrutura da distribuição da renda rural, com o agravamento das condições de severidade da pobreza, coincidindo com outros reflexos das mudanças na política econômica adotada nestes anos, com a transferência de renda dos mais pobres (mais de $50 \%$ da população) para o restante dos indivíduos. Estas evidências associam um caráter concentrador no meio rural, visto que a redução da proporção de pobres se deu às custas dos mais pobres.

As baixas elasticidades calculadas condizem com as baixas rendas médias e a elevada concentração de renda verificadas em todo o período. Os valores associam ao crescimento econômico maior impacto na redução da proporção de pobres, e à distribuição da renda, maior impacto no aumento da renda média desta parte da população e na redução da severidade das condições da pobreza por ela enfrentada. Porém, o próprio crescimento econômico do país não é independente da sua estrutura de distribuição de renda, como discutido no processo histórico da economia brasileira, no qual a concentração de renda representou fator limitante ao próprio processo de crescimento econômico, com conseqüências para o desenvolvimento sócio-econômico do país.

Neste sentido, volta-se à discussão entre a priorização de políticas públicas voltadas para o mercado, em contraposição a políticas de natureza estrutural, tais como reformas nos sistemas de educação e saúde, na estrutura da posse da terra, ou no desenvolvimento de um sistema efetivo de tributação fundiária e trabalhista, consideradas necessárias para quebrar com o círculo vicioso de estagnação econômica.

A aproximação quadrática de Datt para a curva de Lorenz apresentou diferenças substanciais para os índices associados à severidade da pobreza e à insuficiência de renda com relação aos valores calculados pela metodologia de Foster-Greer-Thorbecke, demonstrando maior coerência com a análise gráfica. Os métodos escolhidos têm a vantagem de não utilizar logaritmos, o que permite o uso de rendas nulas, muito significativo nas áreas rurais brasileiras, tendo sido incorporadas para um melhor dimensionamento da pobreza adotando uma postura mais "conservadora".

A abordagem de outras dimensões do problema e formas de cálculo dos índices pode adicionar elementos à análise e compreensão do fenômeno da pobreza nas áreas rurais, assim como apoiar os agentes políticos em suas 
decisões. A análise, no entanto, não pode estar desvinculada das questões culturais e políticas envolvidas, sendo uma questão de natureza multidisciplinar.

Os dados e resultados indicam para a existência da relação entre a persistente condição de pobreza da população rural e as políticas agrária e econômica adotadas no período.

\section{Referências Bibliográficas}

ALDANA, R. L. Dialética do Subdesenvolvimento. 2a edição. Paz e Terra, Rio de Janeiro, 1968. 232p.

BARROS, G. S. C. \& ARAÚJO, P. F. C. de. A política de crédito rural no Brasil: perspectivas para os anos 90. Piracicaba, SP: Departamento de Economia e Sociologia Rural, ESALQ/USP (Relatório de Pesquisa), maio, 1991.

CARVALHO, F. M. A. \& TEIXEIRA, E. C. Políticas governamentais aplicadas ao agronegócio. Caderno de estudos do Departamento de Economia Rural, Universidade Federal de Viçosa, Viçosa, MG, 2005. 70p.

CORRÊA, A.J. Distribuição de Renda e Pobreza na Agricultura Brasileira. Editora Unimep, Piracicaba, SP, 1998. 260p.

DATT, G. Computational tools for poverty measurement and analysis. Washington, D.C. International Food and Nutrition Institute, 1998.

DELGADO, G. C. Expansão e modernização do setor agropecuário no pós-guerra: um estudo da reflexão agrária. Estudos Avançados. 15(43): 157-172, 2001.

MINISTÉRIO DO TRABALHO E EMPREGO (MTE). Disponível em $<$ http://www.mte.gov.br/sal_min/EVOLEISM.pdf > . Acesso em 23/04/2010.

FISHLOW, A. Brazilian Size Distribution of Income. The American Economic Review. V. LXVII (2):391-402. may/1972.

FISHLOW, A. Distribuição de renda no Brasil: Um novo exame. Dados. Rio de Janeiro, 11:10-80, 1973.

FOSTER, J., GREER, J., \& THORBECKE, E. A class of decomposable poverty measures. Econometrica, 52(3):761-766, 1984.

FURTADO, C. A dialética do desenvolvimento. Rio de Janeiro: Fundo de Cultura, 1964.

FURTADO, C. Formação econômica do Brasil. $8^{\text {a }}$ edição, Editora Nacional, São Paulo, 1968. 261p. 
GRAZIANO DA SILVA, J. Progresso técnico e relações de trabalho na agricultura paulista. São Paulo, Hucitec, 1980. 210p.

GREMALDI, A. P. et al. Economia Brasileira Contemporânea, Atlas, 2003.

GRETL. Disponível em: < http://gretl.sourceforge.net/> em março de 2007.

HOFFMANN, R. Contribuição à análise da distribuição da renda e da posse da terra no Brasil. Tese de Livre Docência, Escola Superior de Agricultura Luiz de Queiroz, Universidade de São Paulo, Piracicaba, SP, 1971.

HOFFMANN, R. Considerações sobre a evolução recente da distribuição de renda no Brasil. Revista de Administração de Empresas, 13(4): 7-17, 1973.

HOFFMANN, R. Relações entre pobreza absoluta, renda média e desigualdade da distribuição de renda. Pesquisa e Planejamento Econômico, 25(2):337-358, 1995.

HOFFMANN, R. Elasticidade da Pobreza em Relação à Renda Média e à Desigualdade no Brasil e nas Unidades da Federação. Economia, v6, n², jul/dez, 255-286, 2005.

LAMOUNIER, B.(Coord.) Determinantes políticos da política agrícola: um estudo de atores, demandas e mecanismos de decisão. IPEA: estudos de política agrícola $n^{\circ} 9$, 1994. $58 \mathrm{p}$.

LANGONI, C. G. Distribuição de renda e desenvolvimento econômico do Brasil. Rio de Janeiro, Expressão e Cultura, 1973. 315 p.

LANGONI, C. G. Distribuição de renda: resumo da evidência. Ensaios Econômicos/ Escola de Pós-Graduação em Economia - Instituto Brasileiro de Economia da FGV, 1974. 17, 43 p.

MARINHO, E. \& SOARES, F. Impacto do crescimento econômico e da concentração de renda sobre a redução da pobreza nos estados brasileiros. In XXXI Encontro Nacional de Economia, Porto Seguro, BA, ANPEC, 2003.

MARTINS, J. S. A questão agrária brasileira e o papel do MST. In: João Pedro Stedile (org.). A reforma agrária e a luta do MST. Petrópolis (RJ), Vozes, 1997.

NAKANO, Y. Globalização, competitividade e novas regras de comércio mundial. Revista Economia Política, v. 14, n. 4, out/dez, 1994.

NEDER, H. D. Os efeitos das atividades não agrícolas na distribuição de renda do meio rural do Brasil. XXXIX Congresso Brasileiro de Economia e Sociologia Rural, SOBER, Anais em CD-ROM, Recife, agosto de 2001. 
NEDER, H. D. \& MARIANO DA SILVA, J. L. Pobreza e distribuição de renda em áreas rurais: uma abordagem de inferência. In XXXI Encontro Nacional de Economia, Porto Seguro, BA, ANPEC, 2003.

PINHEIRO, C. P. et al. O desempenho macroeconômico do Brasil nos anos 90. A Economia Brasileira nos Anos 90. BNDES, 1999.

PRADO JR., C. A questão agrária no Brasil. $3^{\text {a }}$ edição. Brasiliense, São Paulo, 1981. 188p.

PEREIRA, L. C. Economia Brasileira: Uma Introdução Crítica. $4^{\text {a }}$ edição. Brasiliense, São Paulo, 1985. 169p.

SINGER, P. Desenvolvimento e repartição da renda no Brasil. In: TOLIPAN, R. \& TINELLI, A. C. (Org.). A controvérsia sobre distribuição de renda e desenvolvimento. Rio de Janeiro, ZAHAR, 1975. p. 73-104.

THEIL, H. Economics and Information Theory. North-Holland, Amsterdam, 1967. 